\title{
Location-dependent maintenance of intrinsic susceptibility to mTORC1-driven tumorigenesis
}

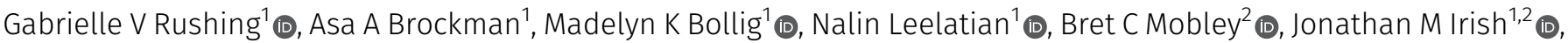

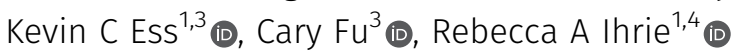

Neural stem/progenitor cells (NSPCs) of the ventricularsubventricular zone (V-SVZ) are candidate cells of origin for many brain tumors. However, whether NSPCs in different locations within the V-SVZ differ in susceptibility to tumorigenic mutations is unknown. Here, single-cell measurements of signal transduction intermediates in the mechanistic target of rapamycin complex 1 (mTORC1) pathway reveal that ventral NSPCs have higher levels of signaling than dorsal NSPCs. These features are linked with differences in mTORC1-driven disease severity: introduction of a pathognomonic TsC2 mutation only results in formation of tumorlike masses from the ventral V-SVZ. We propose a direct link between location-dependent intrinsic growth properties imbued by mTORC1 and predisposition to tumor development.

DOI 10.26508/lsa.201800218 | Received 19 October 2018 | Revised 6 March 2019 | Accepted 7 March 2019 | Published online 25 March 2019

\section{Introduction}

The ventricular-subventricular zone (V-SVZ) is the largest stem cell niche in the mammalian brain and is active during early postnatal development in both human and mouse (Guerrero-Cazares et al, 2011; Sanai et al, 2011). Neural stem/progenitor cells (NSPCs) within the V-SVZ have a positional identity-their dorsal-ventral and medial-lateral location within this spatially extensive stem cell niche predicts the type of neurons produced and correlates with the expression of region-specific transcription factors (Merkle et al, 2007, 2014; Young et al, 2007; Llorens-Bobadilla et al, 2015). However, whether dorsal versus ventral NSPCS have stereotypic signal transduction patterns or differential contributions to neurologic disease is unknown. We hypothesized that positionally linked features predispose cells to differing behaviors when diseaseassociated mutations occur.

The mechanistic target of rapamycin complex 1 (mTORC1) is a central regulator of cell size and growth. Within the V-SVZ, signaling via mTORC1 has been proposed to regulate self-renewal, proliferative divisions, differentiation, and brain ventricle morphogenesis (Paliouras et al, 2012; Foerster et al, 2017; Baser et al, 2019). In the developmental disorder tuberous sclerosis complex (TSC), patients carry mutations in either TSC1 or TSC2, leading to an increase in mTORC1 signaling and tumor formation throughout the body (Crino et al, 2006). In the brain, approximately $80 \%$ of patients develop small periventricular tumors called subependymal nodules and 15\% develop larger, potentially lethal tumors termed subependymal giant cell astrocytomas (SEGAs) (Krueger et al, 2013; Northrup et al, 2013). SEGAs frequently present near the foramen of Monro, a structure which includes the ventral area of the $\mathrm{V}$-SVZ (Katz et al, 2012; Louis DN, 2016). Subependymal nodules and SEGAs are thought to originate from neural stem cells (Ess et al, 2005; Zhou et al, 2011; Feliciano et al, 2012), but the biological mechanisms underlying preferential SEGA localization are unknown. One possible etiology of SEGAs is a distinct ventral cell of origin. Here, patient tumors and mouse models were examined to investigate whether ventral subpopulations of stem cells exhibit a proliferation advantage and are uniquely capable of forming tumors when TSC2 is lost. Fluorescence flow cytometry was used to probe the intrinsic signaling capabilities of dorsal and ventral NSPCs with specific focus on mTORC1-dependent signaling events known to be disrupted in TSC.

\section{Results and Discussion}

SEGA samples from human TSC patients preferentially express the ventral transcription factor NKX2.1

To determine whether patient tumors express factors typical of specific V-SVZ subregions, both periventricular SEGA specimens and cortical hamartomas (tubers) from TSC patients were examined. Empty spiracles homeobox 1 (EMX1), which is expressed in developing cortex and in stem cells of the dorsal V-SVZ, was abundant in tubers (Fig 1A). By contrast, the ventral transcription factor NK2 homeobox 1 (NKX2.1) was not observed in these samples

${ }^{1}$ Department of Cell and Developmental Biology, Vanderbilt University School of Medicine, Nashville, TN, USA ${ }^{2}$ Department of Pathology, Immunology, and Microbiology, Vanderbilt University School of Medicine, Nashville, TN, USA ${ }^{3}$ Department of Pediatrics, Vanderbilt University Medical Center, Nashville, TN, USA ${ }^{4}$ Department of Neurological Surgery, Vanderbilt University Medical Center, Nashville, TN, USA

Correspondence: rebecca.ihrie@vanderbilt.edu 
A

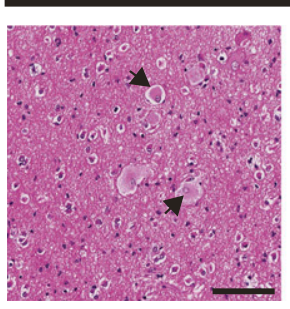

Tubers

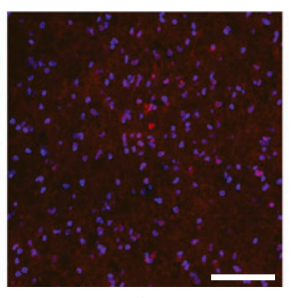

DAPI / EMX1

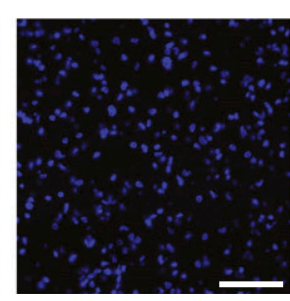

DAPI / NKX2.1

B

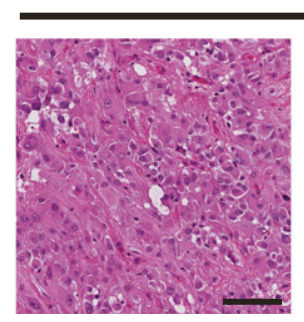

EMX1+ Cells in SEGAs n.s.

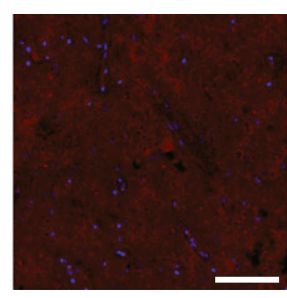

DAPI / EMX1

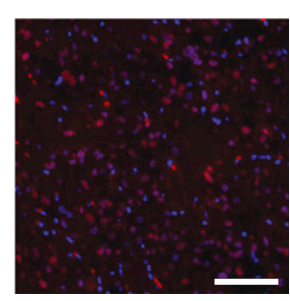

DAPI / NKX2.1
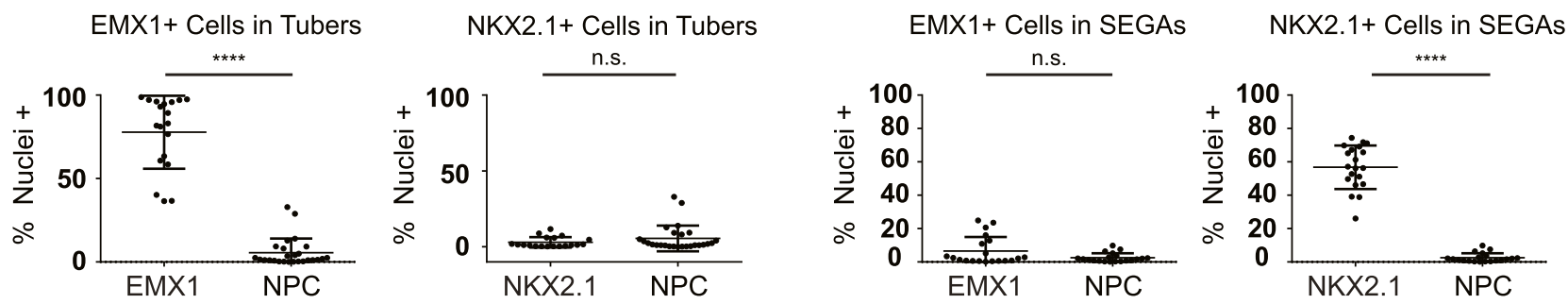

Figure 1. Transcription factors defining dorsal or ventral identity are differentially expressed in dorsal and ventral hamartomas in TSC.

(A) Representative fields from tilescans of human TSC cortical tubers stained with hematoxylin and eosin (left) or for DAPI (blue) and EMX1 (center, red) or NKX2.1 (right, red). Note the enlarged balloon cells (arrows) typical of tubers. Quantification of \% positive nuclei for each factor is shown below. EMX 1 is abundantly expressed ( $P<0.0001$ versus NPC), whereas NKX2.1 is not $(P=0.5809)$. $\mathrm{N}=4$ tubers, each dot $=1$ region of interest $(R O I), 4-5$ ROIs/tuber. (B) Representative fields from tilescans of human SEGA tumors stained with hematoxylin and eosin (left) or for DAPI (blue) and EMX1 (center, red) or NKX2.1 (right, red). Quantification of positive nuclei is shown below, as in (A). In these ventral tumors, EMX1 is not widely expressed $(P=0.3373)$, but NKX2.1 is abundant $(P<0.0001)$. N = 4 SEGAs, each dot $=1$ ROI, 5 ROIs $/$ SEGA. Mann-Whitney tests were used. All scale bars $=100 \mu \mathrm{m}$.

but was abundant in resected SEGA tissue (Fig 1B), consistent with prior case studies of transcript expression (Hewer \& Vajtai, 2015; Hang et al, 2017). EMX1 was largely absent in SEGAs, suggesting that these two differentially localized malformations in TSC patients originate from distinct progenitor populations and that periventricular tumors are enriched for ventral markers.

\section{Ventral stem and progenitor cells have higher mTORC1 signaling than their dorsal counterparts}

To analyze per-cell mTORC1 activity in V-SVZ subpopulations, dorsal and ventral NSPCS were dissected from neonatal mice and cultured as monolayers (Fig S1A). The cultures were first validated by measuring transcripts expressed in the dorsal (Pax6) or ventral V-SVZ (Nkx2.1 and Nkx6.2) (Hack et al, 2005; Kohwi et al, 2005; Waclaw et al, 2006; Merkle et al, 2014; Delgado \& Lim, 2015; Delgado et al, 2016). As expected, NSPCS were enriched for transcription factors present in their $\mathrm{V}$-SVZ region of origin at both the transcript and protein level (Fig S1B and C).

Cultured NSPCS were used for flow cytometric measurement of phosphorylation events downstream of mTORC1 after gating for live, intact single cells (Fig S2A) (Hsu et al, 2011; Saxton \& Sabatini, 2017). Known mTORC1 targets eukaryotic translation initiation factor 4E-binding protein 1 ( $p$-4EBP1 T37/46) and ribosomal S6 protein (p-S6 S240/244) were phosphorylated at increased levels (e.g., a difference of 0.4 in the arcsinh-transformed median fluorescence intensity values, equivalent to an approximately twofold increase) in ventral cells (Fig 2A). Similarly increased levels of phosphorylated signal transducer and activator of transcription 3 (p-STAT3 S727), which is downstream of both the MAPK and mTORC1 pathways, were also observed in ventral cells (Fig 2A). Dependence of these signaling pathways on mTORC1 was confirmed by treatment with rapamycin (Fig $2 \mathrm{~B}$ ). Consistent with the role of this pathway in regulating cell size and translation, ventral cells displayed small but significant differences in forward scatter by flow cytometry, indicating larger median size (Fig S2D). In addition, labeling with O-propargyl-puromycin (OPP) to detect newly translated proteins was elevated in ventral NSCS demonstrating increased protein synthesis (Fig 2C). Phosphorylation events not exclusively or specifically regulated by mTORC1, including p-S6 S235/236 (Fig 2A), p-PLCY Y759, and p-ERK1/2 T202/Y204 (Fig S2C), did not differ significantly between dorsal and ventral cells. Similarly, total (unphosphorylated) levels of 4EBP1, STAT3, or S6 protein were not different between dorsal and ventral cells (Fig S2B). Levels of phosphorylated p38 mitogen-activated protein kinase ( $p$-p38 MAPK T180/Y182) were higher in dorsal NSPCS, and p-Akt S473, upstream of mTORC1, exhibited a nonsignificant trend towards higher levels in dorsal NSPCs, likely because of feedback from mTORC2 (Fig S2C). These differences were retained across multiple passages (data not shown), consistent with previous findings demonstrating maintenance of regional identity and transcription factor expression through at least five passages (Delgado et al, 2016). Addition of media conditioned by the opposite cell type did not affect basal mTORC1 signaling, indicating that these differences are likely not due to differing autocrine stimulation (Fig S2E). Increased mTORC1 activity in ventral cells corresponded with slightly more population doublings per day when compared with their dorsal counterparts (Fig 4A). Critically, tuberin loss, via in vitro Cre transduction of cultures derived from $T s c 2^{f l / f l}$ animals, resulted in a much greater difference between dorsal and ventral cells, with ventral cells 
A Cultured wild-type mouse NSCs, postnatal day 2
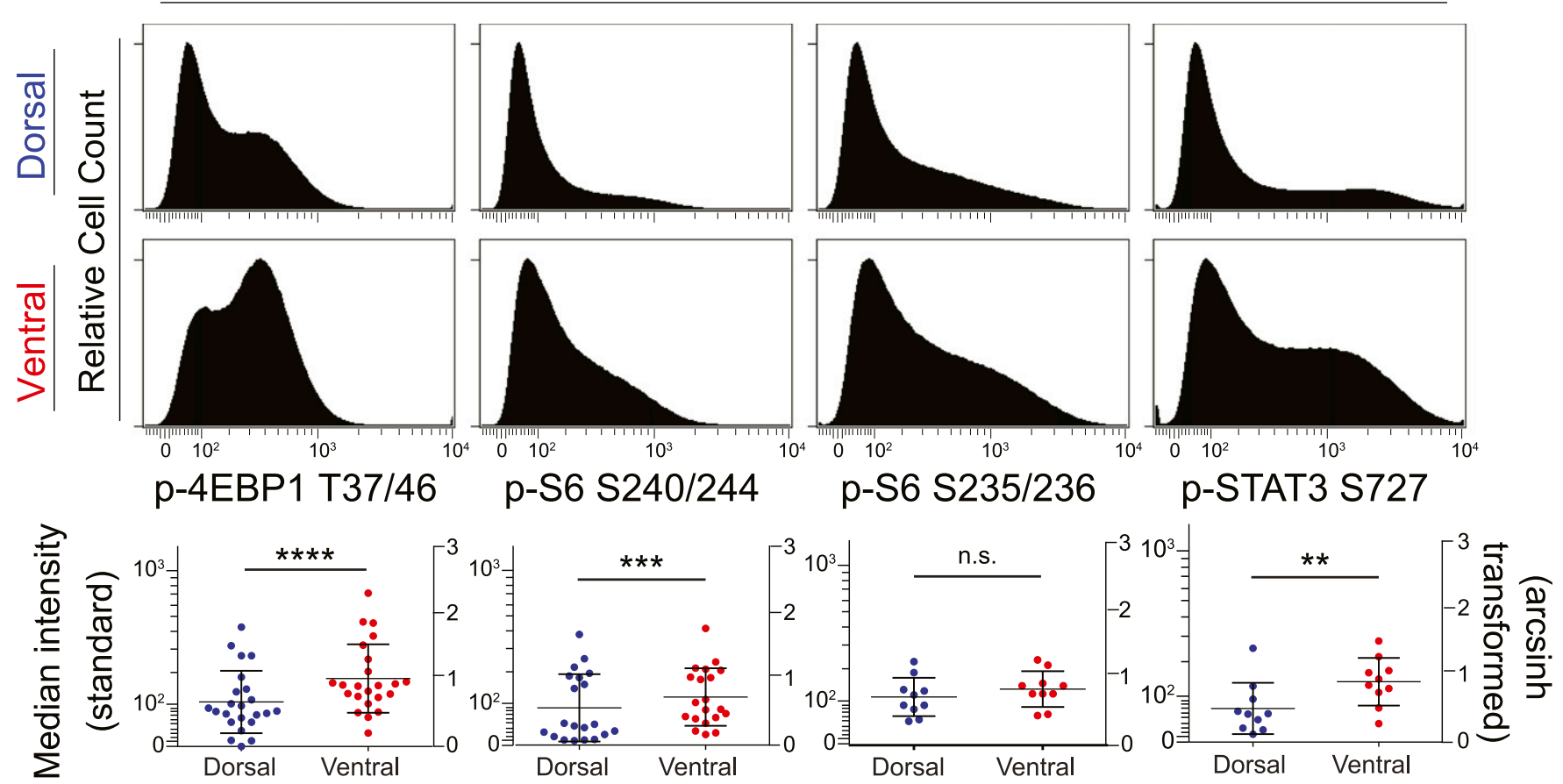

B Dorsal cultured wild-type mouse NSCs, postnatal day 2
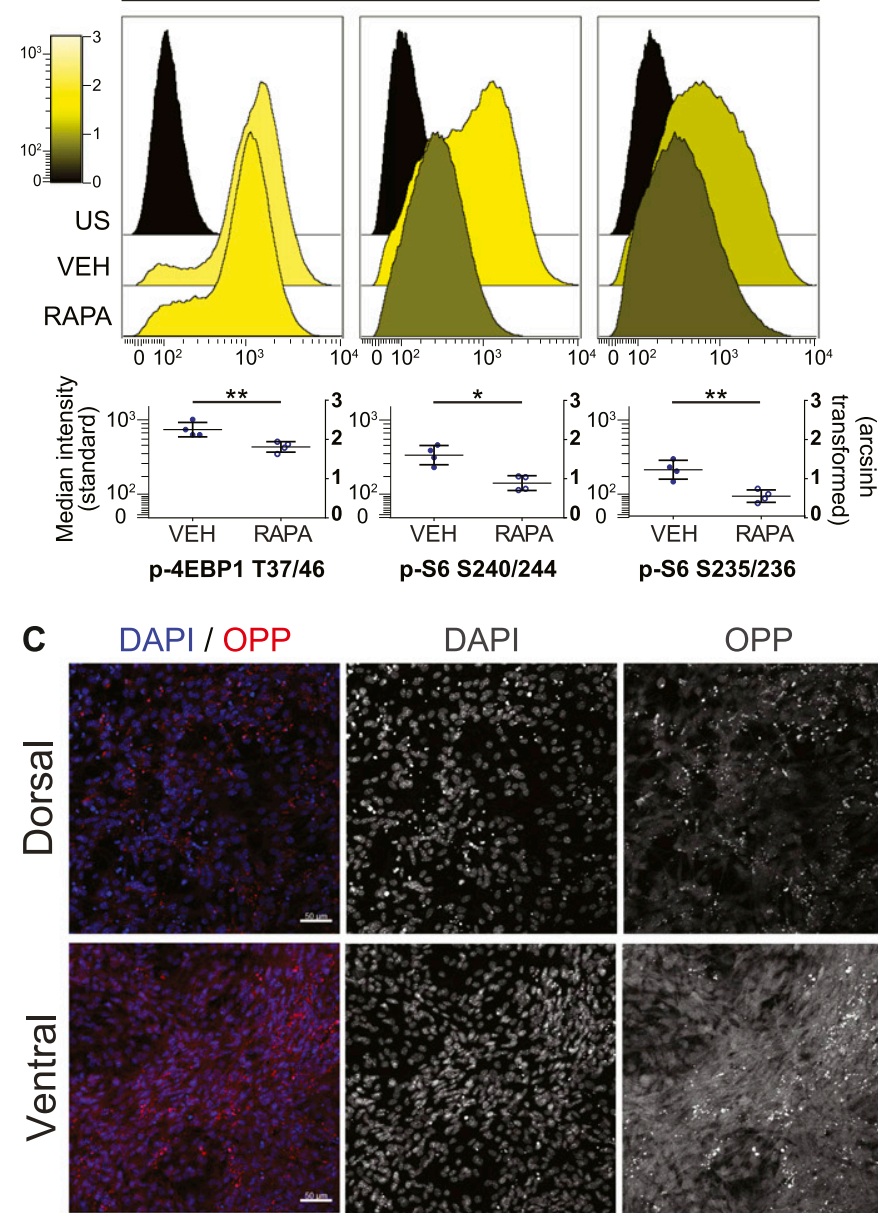

DAPI

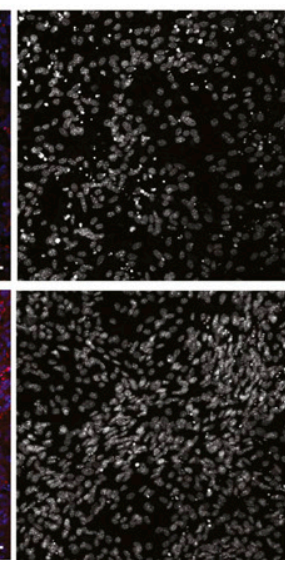

OPP

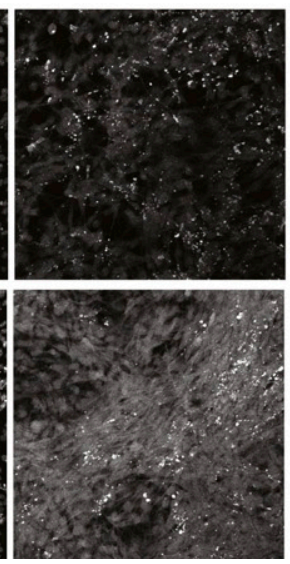

Ventral cultured wild-type mouse NSCs, postnatal day 2

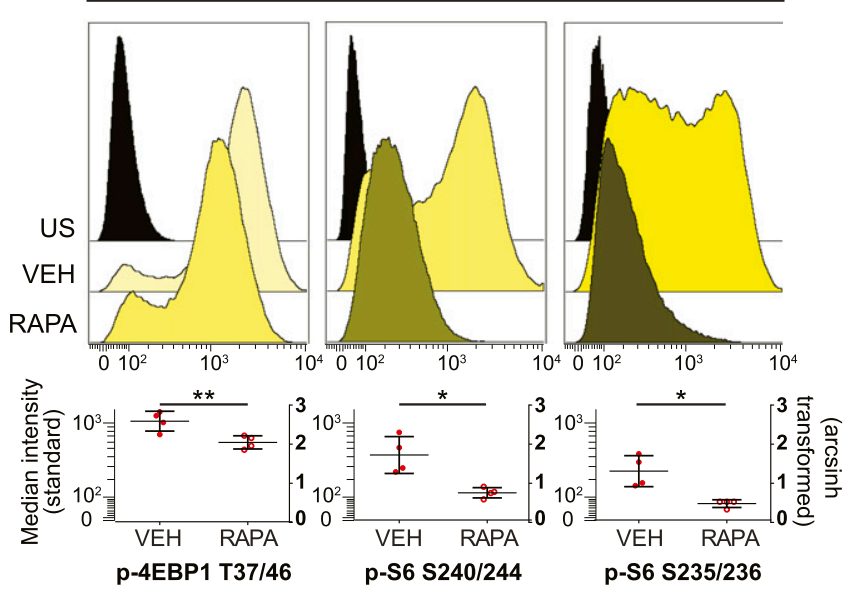

DAPI / OPP
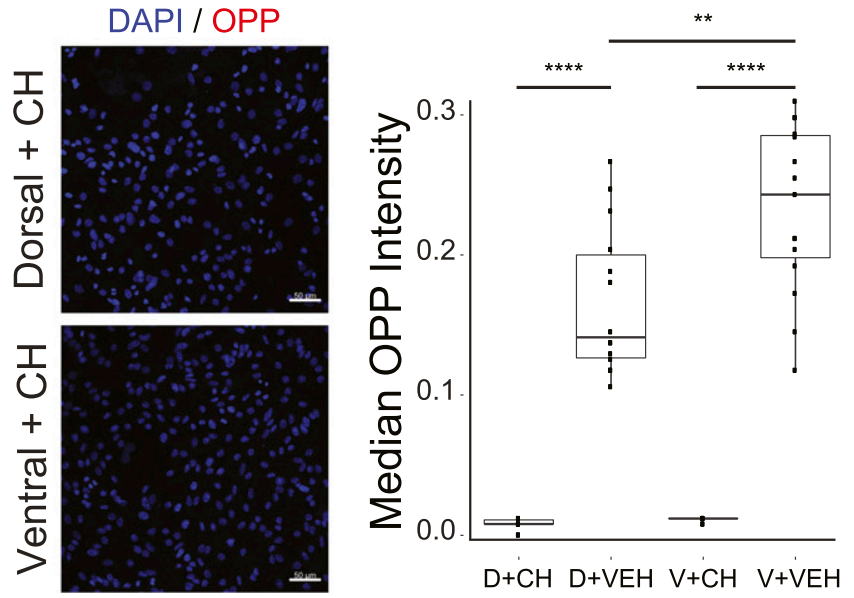
exhibiting approximately twice as many doublings per day (Fig 4B). These data indicate that ventral cells have a disproportionate proliferative advantage when mTORC1 signaling is disinhibited. Correspondingly, phosphorylation of 4EBP1 increased in both dorsal and ventral cultures upon tuberin removal, but dorsal-ventral differences remained (Fig 4C).

\section{Elevated ventral mTORC1 signaling is most evident in transit-amplifying cells}

In addition to quantification in cultured progenitor cells, established protocols for acute dissociation and flow cytometric analysis of adult (P30) V-SVZ tissue were adapted to include fixation and measurement of intracellular antigens (Codega et al., 2014; Leelatian et al., 2017; Pastrana et al., 2009) (Fig 3A). Sequential biaxial gating was used to identify live intact single cells and specific V-SVZ cell types (Fig 3B). Cells collected from the ventral V-SVZ showed increased levels of p-4EBP1 T37/46 in the transit amplifying progenitor cell (TAP) population when compared with dorsal V-SVZ cells (Fig 3B and C), although differences in $\mathrm{p}-\mathrm{S} 6$ S240/244 were not significant (Fig S3A). Surprisingly, activated neural stem cells (aNSCS) from the dorsal V-SVZ displayed slightly elevated levels of p-S6 S240/244 when compared with ventral aNSCs using this approach (Fig S3A), whereas no significant differences between dorsal and ventral were observed in other populations.

To complement these flow cytometric analyses, immunofluorescence was used to localize phosphoproteins within the intact V-SVZ of postnatal day-30 wild-type mice. Doublecortin (DCX)-positive neuroblasts were excluded as these migratory cells may have had either a dorsal or ventral origin (Lois \& Alvarez-Buylla, 1994; Sawamoto et al, 2006). Robust staining of p-S6 S240/244 within the ventral V-SVZ was observed with significantly less abundant and intense staining in the dorsal niche (Fig S3B). Perinatal human brain V-SVZ exhibited a similar pattern of staining, with the ventral region displaying increased p-S6 S240/244 (Fig S3C). To identify TAP cells, measurement of phosphoprotein expression was then limited to Mash1-positive cells in postnatal day-30 wild-type mice. In these analyses, ventral V-SVZ cells had higher per-cell levels of both p-4EBP1 T37/46 and p-S6 S240/244 (Fig 3D and E).

mTORC1 signaling has been proposed as a key regulator of the activation of adult neural stem cells and expansion of the transit- amplifying progenitor pool (Paliouras et al, 2012). Prior reports have variably identified cells with detectable mTORC1 activity as transitamplifying progenitors ( $C$ cells) and GFAP+ cells, including B1 stem cells (Paliouras et al, 2012; Hartman et al, 2013). Here, mTORC1 signaling was observed across the V-SVZ lineage, but differences in mTORC1 signaling between dorsal and ventral subpopulations were most evident within the TAP population. Consistent with these results, others have observed this progenitor population to have the highest level of protein synthesis compared with other lineage stages (Baser et al, 2019). High signaling in ventral cells was specific to the mTORC1 pathway, with p-4E-BP1 displaying the most robust difference in multiple approaches. This elevated phosphoprotein abundance was not observed across all proliferative signaling pathways, and p-p38 MAPK was elevated in dorsal progenitors, a feature not previously appreciated. These data reveal further potential modes of proliferative signaling outside of the mTORC1 pathway that may be dorsally enriched and highlight the selective enhancement of mTORC1 activity in ventral cells.

\section{Early tumor-like lesions develop exclusively after ventral-specific removal of TsC2 in the mouse}

We hypothesized that the increased basal levels of mTORC1 signaling in ventral cells would lead to increased susceptibility to tumor formation versus dorsal counterparts. To directly test whether ventral NSPCS preferentially drive tumor development in a model of TSC, subregion-specific modulation of mTORC1 pathway activity was achieved using a conditional allele of TsC2 (Fu \& EsS, 2013) in combination with the V-SVZ subregion-specific Cre alleles Emx1 ${ }^{\text {Cre }}$ (Kessaris et al, 2006; Young et al, 2007) or Nkx2.1 ${ }^{\text {Cre }}$ (Xu et al, 2008) to ablate tuberin expression in the dorsal or ventral V-SVZ, respectively. EMX1 is expressed in the developing telencephalic cortex (Gorski et al, 2002) and labels dorsal aspects of the adult V-SVZ comprising approximately $35 \%$ of the total niche (Gorski et al, 2002; Young et al, 2007). In contrast, NKX2.1 is expressed in the ventral embryonic forebrain (Sussel et al, 1999) and persists in the ventral-most tip of the lateral ventricle, contributing to approximately 5\% of the total niche (Young et al, 2007; Lopez-Juarez et al, 2013; Merkle et al, 2014; Delgado \& Lim, 2015). Both Cre drivers resulted in efficient loss of tuberin in targeted regions, with $79 \%$ or more of targeted V-SVZ cells exhibiting no detectable protein (Fig S4A-D), consistent with prior reports (Fu \& Ess, 2013).

Figure 2. Ventral mouse V-SVZ cells exhibit higher mTORC1 activity than dorsal cells and are responsive to rapamycin.

(A) Representative histograms (from individual cultures) and graphs of median fluorescence intensity, relative to unstained samples, of phosphorylated proteins measured by flow cytometry. Dorsal: top and ventral: bottom. Each dot on graph represents an independent biological replicate (one culture from a P2 mouse). Left scale: $\log _{10}$ and right scale: arcsinh transformed values. Events indicating mTORC1 activity are significantly elevated in ventral cells ( $p-4 \mathrm{EBP} 1 \mathrm{T37} / 46, P<0.0001 ; \mathrm{p}-\mathrm{S} 6 \mathrm{~S} 240 / 244, P=$ 0.0005 ; $p$-STAT3 S727, $P=0.0026$ ), whereas other events do not differ ( $p$-S6 S235/236, $P=0.1617$ ). A difference of 0.4 (as in the case of $p$ - 4 EBP1) on the arcsinh scale represents an approximately twofold difference in total phosphorylated epitope levels per cell. Paired t tests were used. (B) Representative histograms (top) and graphs (bottom) of unstained (US), vehicle-treated (VEH), and rapamycin-treated (RAPA) dorsal (left) and ventral (right) cultures for the indicated phosphoproteins. The median fluorescence intensity for each phosphoprotein is graphed using a standard $\log _{10}$ scale (left) and the arcsinh-transformed scale (right), with both vehicle and rapamycin-treated samples shown relative to unstained cells. Both dorsal and ventral cultured NSPCs respond to rapamycin treatment (30 nM, $24 \mathrm{~h}$ ) showing decreased signal compared with vehicle (30 nM DMSO, 24 h). Paired $t$ tests were conducted comparing VEH with RAPA: dorsal p-4EBP1 T37/46 ( $P=0.0083), p-S 6$ S240/244 ( $P=0.0309)$, p-S6 S235/236 (0.0092); ventral p-4EBP1 T37/46 (0.0018), p-S S240/244 (0.0157), p-S6 S235/236 (0.0188). N = 4, each N represents cells cultured from an individual P2 mouse. (C) Representative images of dorsal and ventral cultured NSPCs stained for nuclei (DAPI, blue) and OPP (red), which labels newly translated proteins; left (merged image), right (individual grayscale images). Middle: representative images of dorsal and ventral cultured NSPCs pretreated for $30 \mathrm{~min}$ with $100 \mu \mathrm{g} / \mathrm{ml} \mathrm{cycloheximide} \mathrm{(CH),} \mathrm{an} \mathrm{inhibitor} \mathrm{of} \mathrm{protein}$ synthesis. Right: box and whisker plot showing quantification of median OPP pixel intensity for each condition (arbitrary units). Scale bars, $50 \mu \mathrm{m}$. $\mathrm{N}=3$ for vehicle-treated, $\mathrm{N}=1$ for $\mathrm{CH}$-treated. Each $\mathrm{N}=$ cells from an individual P2 mouse. Repeated measures ANOVA was conducted in GraphPad Prism ( $P<0.0001)$ followed by Sidak's multiple comparisons test. For all graphs, bars represent mean \pm SD. 
A

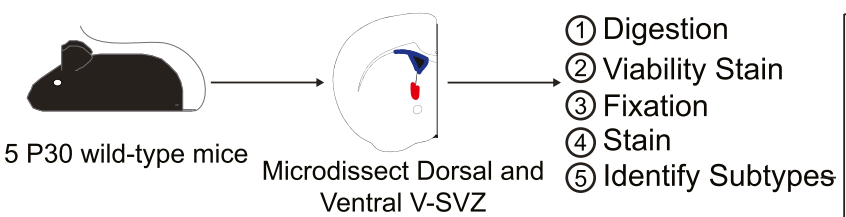

(1) Digestion

Stain

(4) Stain

Ventral V-SVZ

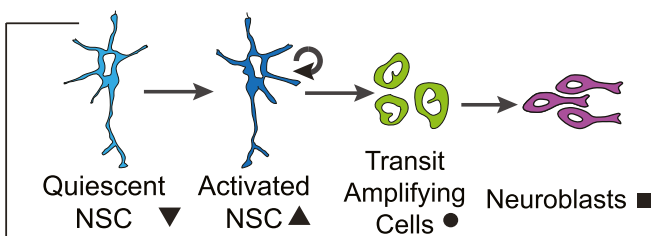

B
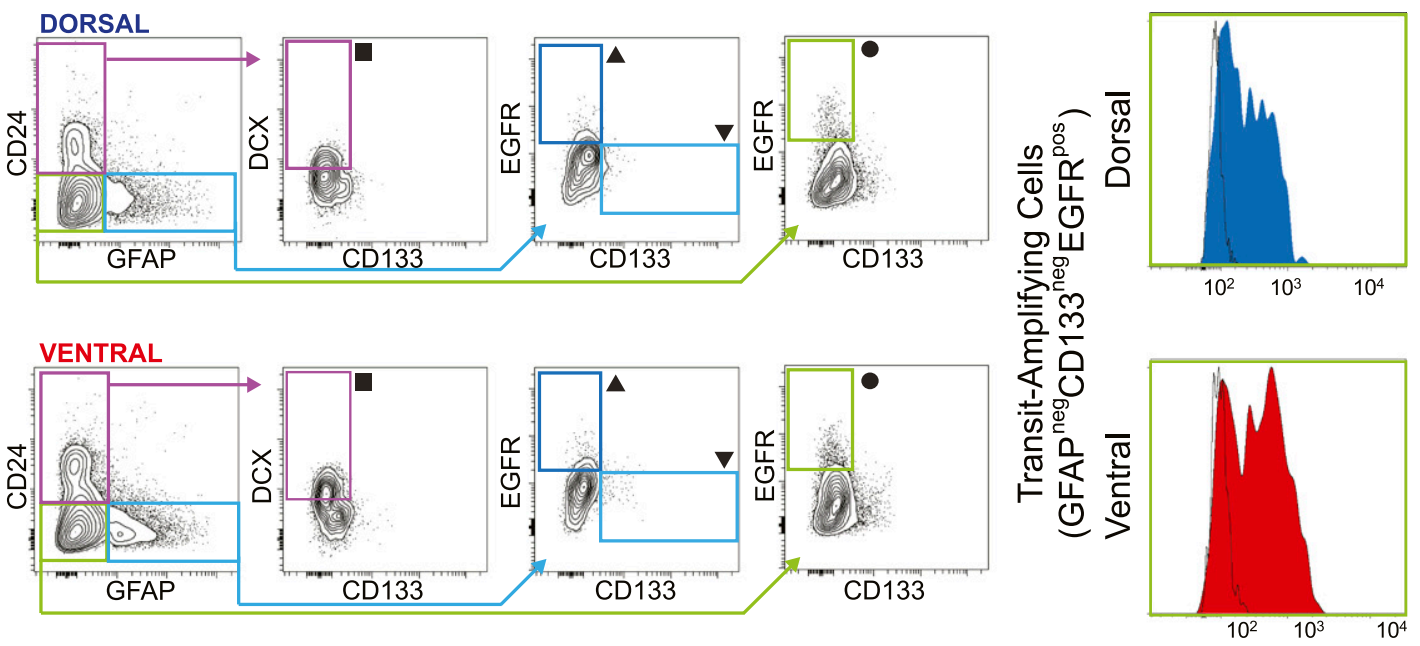

C

p-4EBP1 T37/46
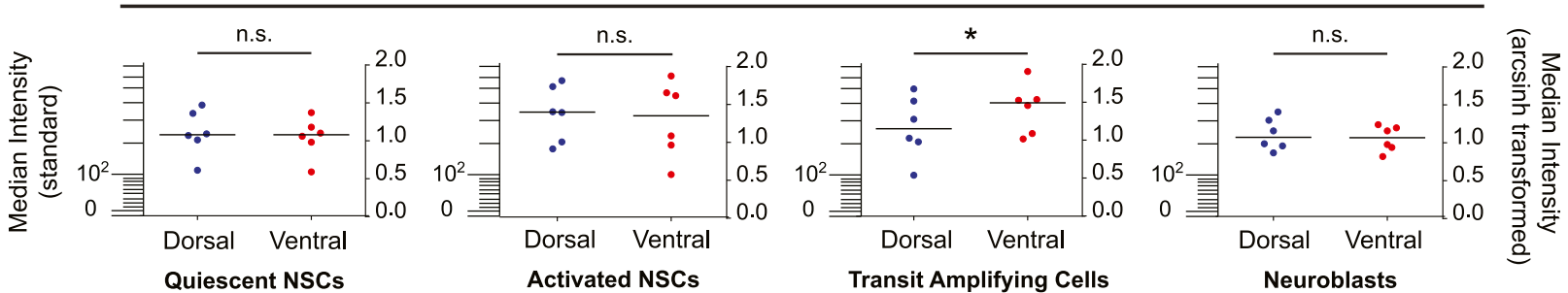

D Wild-type Postnatal Day 30 Mouse V-SVZ
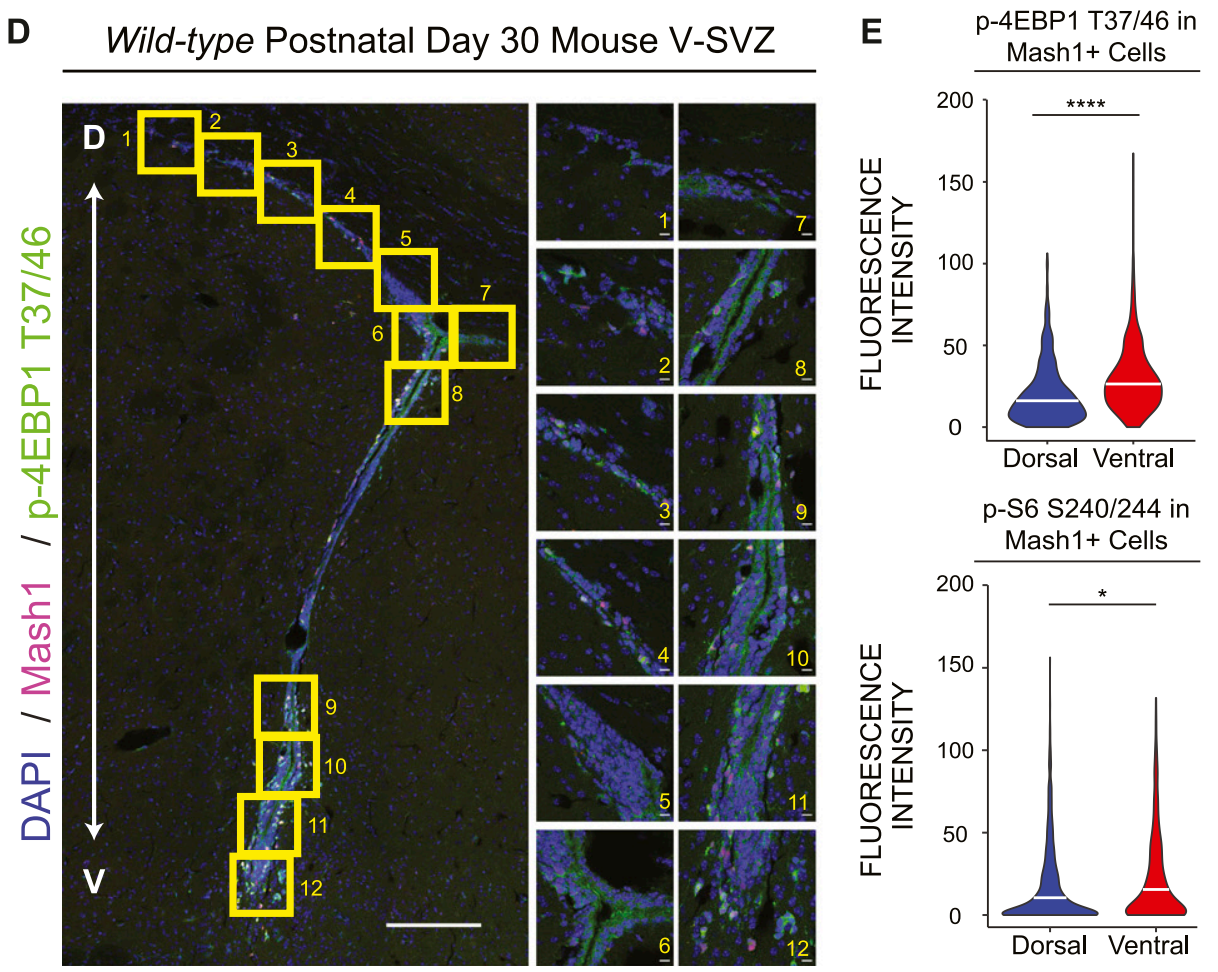
At P7, epilepsy and perinatal lethality were observed in $\mathrm{Em} \times 1^{\mathrm{Cre}}$; $T_{S C 2}{ }^{F l / F I}$ mice (Fu \& ESS, 2013) (data not shown), but tumor formation was not reproducibly evident (Fig 4E). By contrast, at the same time point, large aberrant GFAP-positive cellular collections were ob-

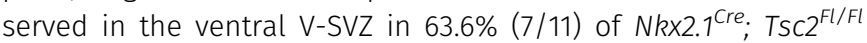
animals, with $27.3 \%(3 / 11)$ exhibiting larger tumor-like protrusions in the third ventricle (Fig 4F and G). These phenotypes were not found in controls (Fig 4D) or animals with dorsal loss of tuberin protein, with only one $E m \times 1^{C r e}$; TsC2 ${ }^{\mathrm{Fl} / \mathrm{Fl}}$ animal presenting with a small $(<10$ nuclei) cell cluster near the ventral V-SVZ (Fig $4 \mathrm{H}$ ). Clusters of abnormal cells expressed variable high GFAP and p-S6 (Fig 4F and $\mathrm{G}$ ) and exhibited densely packed, hyperchromatic nuclei (Fig S4E and F), similar to prior reported models and human SEGAs.

Until now, it has not been shown that differences within the same neural stem cell niche affect susceptibility to tumor development. Central questions within the example case of TSC have been whether SEGAs originate from smaller tumors and whether their larger size and stereotypic ventral presentation is due exclusively to microenvironmental factors-a model postulated in prior animal studies (Zhou et al, 2011). Previous TSC models removed the tuberin binding partner hamartin (encoded by TsC1) throughout the embryonic or postnatal niche and observed structural abnormalities in the lateral ventricle (Zhou et al, 2011; Magri et al, 2013), but no studies have assessed the specific contributions of V-SVZ subpopulations to the development of these features. An additional mouse model co-deleted TsC1 and Pten in postnatal NSCs and found tumors that closely recapitulated human tumors via hematoxylin and eosin staining (Zordan et al, 2018); however, to date, no TSC patients have been reported to have a mutation in Pten (Martin et al, 2017). Although we cannot fully exclude the possibility that dorsal V-SVZ progenitors may also develop into nodules given additional time, the selective, robust generation of tumor-like growths from a relatively small region of the niche indicates a marked sensitivity to the effects of Tsc2 mutation within ventral V-SVZ cells. The data here argue that periventricular tumors in TSC are largely due to the unique susceptibility of ventral NSPCS to mTORC1 dysregulation: only Nkx2.1 ${ }^{\text {Cre }}$; $\mathrm{TSC2}^{\mathrm{Fl} / \mathrm{Fl}}$ animals reliably developed tumor-like cellular protrusions in the V-SVZ and third ventricle at the time points examined, and tuberin loss in cultured ventral cells increased their rate of doubling beyond that seen in matched dorsal cells. Coupled with the specific absence of EMX1 and frequent expression of NKX2.1 in human SEGAs, these findings indicate that ventral neural progenitors defined by NKX2.1 expression and elevated mTORC1 signaling are likely the cells of origin for large tumors in TSC.
Heterotopic transplantation experiments and the study of cultured progenitor cells have demonstrated that the transcriptional identity of V-SVZ cells is at least partially cell intrinsic (Merkle et al, 2007; Delgado et al, 2016). Transcription factors appear to be crucial in initiating or maintaining this feature, as forced expression of ventral transcription factors such as Gli1 can alter subsequent neuronal identity (Ihrie et al, 2011). Similarly, embryonic loss of Nkx2.1 results in respecification of cells from a ventral fate to a dorsal fate (Sussel et al, 1999). The differences in mTORC1 signaling identified here show that beyond transcriptomic heterogeneity, an additional level of functional heterogeneity is coupled to position within the V-SVZ. These findings raise the questions of whether identity-associated transcription factors are determinants of basal signaling levels and how early in neural development these signaling states might emerge. If signaling controls identity, it may be possible to productively modulate signaling to alter cell identity. Alternatively, if identity controls signaling, future therapeutic approaches could exploit this specificity to target particular pools of NSPCS in disease states without compromising the entire niche. Collectively, these findings suggest that brain tumors derived from different NSPC origins are distinct diseases requiring differential treatment regimens-a concept with application to other solid tumors, including malignant brain tumors and tumors in epithelia organized along dorsoventral or rostrocaudal coordinates.

\section{Materials and Methods}

\section{Contact for reagent and resource sharing}

Further information and requests for resources, protocols, and reagents should be directed to and will be fulfilled by the Lead Contact, Rebecca Ihrie (rebecca.ihrie@vanderbilt.edu).

\section{Animals}

All animal procedures were carried out in accordance with institutional (Institutional Animal Care and Use Committee) and National Institute of Health guidelines. Mouse lines used were of a mixed background (primarily C57 BL/6J with $129 \mathrm{~S} 6$ and CD1). Critically, for each mouse experiment, the controls were littermates and thus on an equivalent genetic background. If sufficient numbers of wild-type mice were not available in the colony for an experiment, wild-type $\mathrm{C} 57 \mathrm{BL} / 6 \mathrm{~J}$ mice were ordered from Charles River Laboratories. For cultures, P2 C57 BL/6J pups were used. For

Figure 3. The TAP population exhibits the highest mTORC1 signaling differences between dorsal and ventral regions.

(A) Cartoon schematic outlining prospective isolation from dissection to cell identification. (B, C) Biaxial gating strategy to obtain V-SVZ cell types. Symbols at terminal gates correspond to cell types in (C). To the right are representative histograms showing intensity of $p-4 E B P 1$ T37/46 signal in freshly isolated dorsal (blue) and ventral (red) TAPs. Black histogram outline shows the fluorescence minus one control for each sample. (c) Graphs show median fluorescence intensity data for p-4EBP1 T37/46 from 7 sets of 15 pooled mice each (105 total mice); left: standard scale and right: arcsinh-transformed. p-4EBP1 T37/46 is elevated in ventral TAPs relative to dorsal $(P=0.0175$, paired $t$ test, bar $=$ median) but is not different in the other cell types shown $(q N S C s[P=0.1931]$, aNSCs $[P=0.5853]$, and neuroblasts $[P=0.1374]$ ). (D) Representative tilescan confocal images of V-SVZ stained for DAPI (blue), Mash1 (red), and p-4EBP1 T37/46 (green), with boxed areas highlighted to the right. Scale bars: $100 \mu \mathrm{m}$ (tilescan), $10 \mu \mathrm{m}$ (63× images). (E) Quantification of per-cell intensity for p-4EBP1 T37/46 (top: 1,026 dorsal and 590 ventral cells total) and p-S6 S240/244 (bottom: 1,306 dorsal and 805 ventral cells) in confocal images. Both phosphorylation events are elevated in ventral Mash1+ cells relative to dorsal ( $P<0.0001$ [p-4EBP1] and $P=0.0161$ [p-S6 S240/244], Wilcoxon signed rank tests). Each experiment: $\mathrm{n}=4 \mathrm{mice}, 3$ sections $/$ mouse. For all graphs, bars represent mean \pm SD. 
A Doublings per day in Tsc2 +/+ NSCs (no CRE)

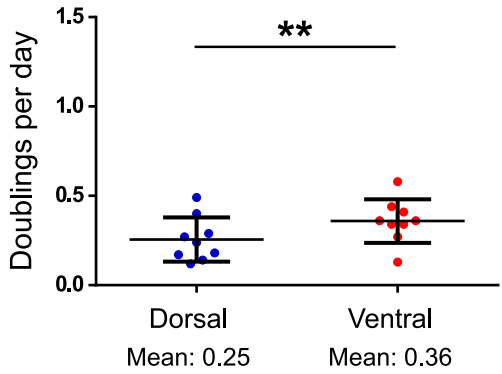

B Doublings per day in Tsc2 fl/fl NSCs treated with Ad:CMV-Cre

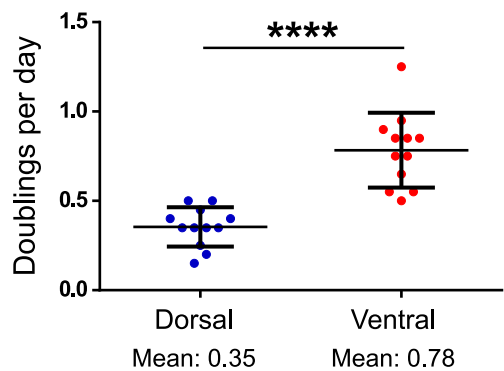

C

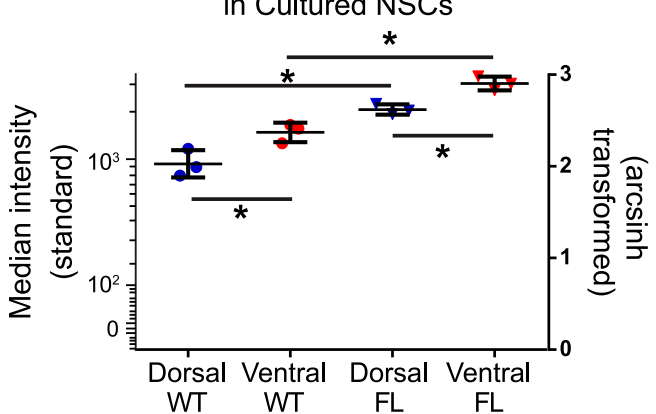

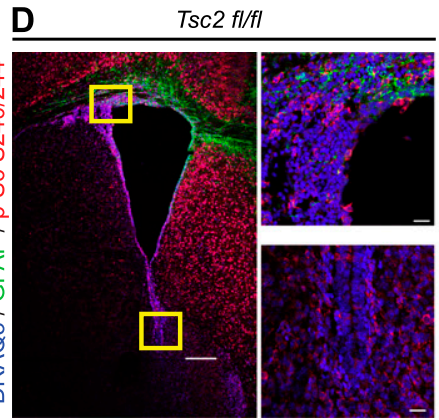

E Emx1-Cre; Tsc2 flffl

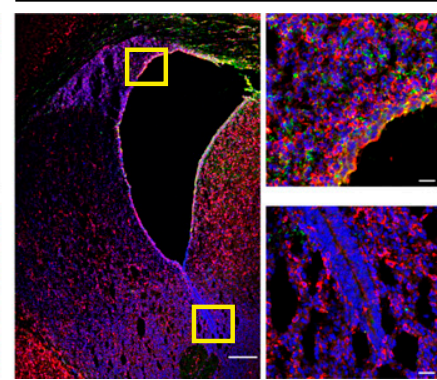

F $\quad N k \times 2.1-\mathrm{Cre} ; \mathrm{Tsc} 2 \mathrm{fl} / \mathrm{fl}$

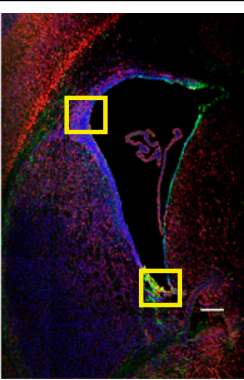

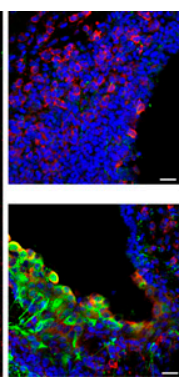

G Nkx2.1-Cre; Tsc2 ff/ff

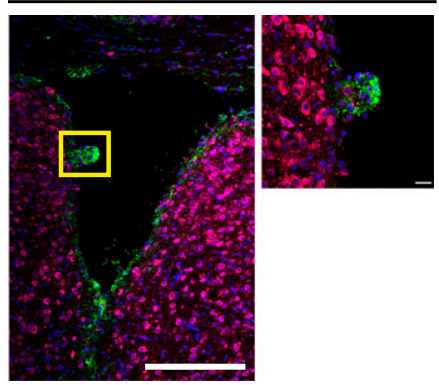

\section{H} Small GFAP+ Cluster ( $<10$ nuclei) Lateral Ventricle

Large GFAP+ Cluster ( $>10$ nuclei) Lateral Ventricle

Large GFAP+Cluster (>10 nuclei) 3rd Ventricle $\frac{\text { Emx1-Cre;Tsc2 fl/fl }}{1 / 13(7.69 \%)} \frac{\text { Nkx2.1-Cre;Tsc2 fl/fI }}{2 / 11(18.2 \%)}$

$0 / 13(0.00 \%)$

$7 / 11(63.6 \%)$

$0 / 13(0.00 \%)$

$3 / 11(27.3 \%)$

Figure 4. Ventral-specific removal of Tsc2 leads to more rapid doubling time, elevated mTORC1 activity, and abnormal growth in the V-SVZ.

(A) Graph illustrating population doublings per day in wild-type dorsal and ventral cultures. Ventral cells exhibit slightly increased doubling times as compared with dorsal, consistent with previous findings (Delgado et al, 2016). $\mathrm{N}=3$ mice counted three times. Paired $t$ test, $P=0.0018$. (B) Graph illustrating doublings per day in Tsc2 ${ }^{f / f l}$ dorsal and ventral cultures treated with Ad:CMV-Cre. When tuberin is lost, ventral cells double twice as fast as their dorsal counterparts do. $\mathrm{N}=4$ mice, counted four times. Paired $t$ test, $P=0.0001$. (C) Graph showing the median fluorescence intensity of $\mathrm{p}-4 \mathrm{EBP} 1 \mathrm{T37} / 46$ in wild-type and Tsc2 ${ }^{f / f l}$ dorsal and ventral cultures (treated with Ad:CMVCre). High signaling is observed as compared with dorsal in wild-type ventral cultures. Upon Tsc2 removal, both dorsal and ventral cultures exhibit higher p-4EBP1 T37/46 than wild-type but dorsal-ventral differences are maintained. Repeated measures ANOVA with Holm-Sidak's multiple comparisons test, $P=0.0005$. $N=3$ mice per condition. (D-G) 10- $\mu \mathrm{m}$ P7 brain sections stained for DRAQ5 (nuclei, blue), GFAP (green), and p-S6 S240/244 (red). (D) Representative confocal images of V-SVZ subregions are shown for Tsc2 fl/fl control mouse. (E) Emx1-Cre; Tsc2 ${ }^{f / f l}$ animals do not exhibit tumor growth. (F, G) Representative confocal images for Nkx2.1-Cre; Tsc2 ${ }^{f / f l}$ reveal GFAP+ cellular protrusions in the ventral V-SVZ (F). (G) A larger tumor-like structure is apparent in the third ventricle (G). (H) Phenotypic summary of all mouse models. All images: scale bar $=200 \mu \mathrm{m}$ and insets $=20 \mu \mathrm{m}$. For all graphs, bars represent mean $\pm \mathrm{SD}$.

experiments using wild-type adult animals, P30 male C57 BL/6J animals were used. For subregion-specific cre lines $\left(E m \times 1^{\mathrm{Cre}}\right.$; $T s c 2^{f l / f l}$ and $\left.N k \times 2.1^{C r e} ; T s c 2^{f l / f l}\right)$, P7 animals were analyzed because of perinatal lethality observed in the $E m \times 1^{C r e} ; T_{s c 2}{ }^{f l / f l}$ animals (Fu \& Ess, 2013). Tsc2 ${ }^{f l / f l}$ animals were a kind gift from Kevin Ess and Cary Fu

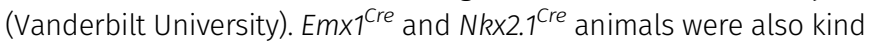
gifts from Kevin Ess and Cary Fu, with original orders made from The Jackson Laboratory (https://www.jax.org/).

\section{Mouse genotyping}

\author{
TSC2: TGGCAGGACAGAGGGTCATCATGG (TSC2-Forward), TTCAGAGTC- \\ ACCTGGCAGGCTCG (TSC2-Reverse); \\ Cre: TAAAGATATCTCACGTACTGACGGTG (nlsCre-Forward), TCTCT- \\ GACCAGAGTCATCCTTAGC (nlsCre-Reverse).
}

\section{Human tissue samples}

De-identified GW33+0 brain tissue sections were provided by the University of California Pediatric Neuropathology Consortium. All human tuber and SEGA tissues were obtained with consent under Vanderbilt University Institutional Review Board \#180238 and \#130550. Authors attest that experiments conformed to the principles set out in the World Medical Association Declaration of Helsinki and the Department of Health and Human Services Belmont Report. Information on age at resection and clinical history is included in the table below.

\section{Primary cell cultures}

For experiments using cultured V-SVZ cells, the cells were prepared from postnatal day-2 wild-type pups as previously described 
Resected tissue information.

\begin{tabular}{l|lll} 
Case no. & Age at resection & Gender & Clinical history \\
\hline 1 & 11 & Male & $\begin{array}{l}\text { TSC, SEGA tumor, foramen of } \\
\text { Monro }\end{array}$ \\
\hline 2 & 12 & Male & $\begin{array}{l}\text { TSC, SEGA tumor, left foramen } \\
\text { of Monro }\end{array}$ \\
\hline 3 & 17 & Male & $\begin{array}{l}\text { TSC, SEGA tumor, right } \\
\text { foramen of Monro }\end{array}$ \\
\hline 4 & 3 & Female & $\begin{array}{l}\text { TSC, SEGA tumor, left foramen } \\
\text { of Monro }\end{array}$ \\
\hline 5 & 2 & Female & TSC, cortical tuber tissue \\
\hline 6 & 2 & Female & TSC, cortical tuber tissue \\
\hline 7 & 2 & Male & TSC, cortical tuber tissue \\
\hline 8 & GW33+0 & $\begin{array}{l}\text { Not } \\
\text { provided }\end{array}$ & $\begin{array}{l}\text { Perinatal human brain tissue, } \\
\text { COD not brain-related }\end{array}$ \\
\hline
\end{tabular}

(Merkle et al, 2007; Delgado et al, 2016). In brief, dorsal and ventral V-SVZ tissue was minced and incubated with $0.25 \%$ Trypsin-EDTA for 20 min at $37^{\circ} \mathrm{C}, 5 \% \mathrm{CO}_{2}$ followed by mechanical dissociation and plating in N5 media. Cells were fed every other day and passaged upon confluence. Dorsal and ventral cells were passaged on the same days and plated at equivalent numbers. For experiments using Tsc2 ${ }^{\mathrm{fl} / \mathrm{fl}}$ cells, Ad:CMV-Cre (Vector Biolabs) was added at passage 1 at a concentration of $1 \times 10^{7} \mathrm{pfu} / \mathrm{ml}$. dTomato expression was confirmed $72 \mathrm{~h}$ after virus addition using epifluorescence microscopy and subsequently confirmed via flow cytometry.

\section{Flow cytometry-cultured cells}

All files associated with this manuscript, including cultured cells and dissociated tissue, are available on FlowRepository under the ID FR-FCM-Z2ZZ (Spidlen et al, 2012). Cultured cells were collected for flow cytometry experiments at passage 2 using dissociation protocols as previously described (Irish et al, 2010). In brief, the cells were treated with Accutase for 15 min at $37^{\circ} \mathrm{C}, 5 \% \mathrm{CO}_{2}$ on a nutator followed by mechanical dissociation (trituration) into a single-cell suspension. The cells were then pelleted by centrifugation (5 min, 0.3 RCF) and resuspended in equivalent volumes of their original media in round bottom tubes (352052; Corning). The cells in tubes then rested at $37^{\circ} \mathrm{C}, 5 \% \mathrm{CO}_{2}$ for $2 \mathrm{~h}$, with Alexa Fluor $700-\mathrm{SE}$ dye (A20010; Life Technologies) added for the last 15 min of incubation to label non-intact cells. Subsequently, the cells were fixed with a final concentration of $1.6 \%$ paraformaldehyde for $20 \mathrm{~min}$ at room temperature, washed with $1 \times$ PBS, and spun for $5 \mathrm{~min}$ at $800 \mathrm{~g}$ at room temperature. The tubes were decanted and the cells were resuspended in the void volume by vigorous vortexing. Once resuspended, $100 \%$ cold methanol was added. The cells were incubated at $-20^{\circ} \mathrm{C}$ for 20 min and either used immediately for flow cytometry experiments or stored at $-80^{\circ} \mathrm{C}$ until staining. All antibody clones and dilutions are listed in Table S1.

The experiments were run on either BD LSR II or Fortessa 5-laser instruments. Single fluorophore-labeled beads and unstained cell lines were used as compensation and sizing controls. Signaling was quantified as the fold change in per-cell phosphoprotein median fluorescence intensity of stained samples compared with unstained samples from the same experiment. In the case of cells with the dTomato RFP reporter (Ai14), stained samples were compared with reporter-only samples. The inverse hyperbolic sine (arcsinh) with a cofactor was used to compare samples as previously described (Irish et al, 2010). The arcsinh median of intensity value $x$ with cofactor $c$ was calculated as $\operatorname{arcsinh} c(x)=\ln \left(x / c+\sqrt{ }\left((x / c)^{2}+1\right)\right)$. The cofactor (c) is a fluorophore-specific correction for signal variance. All analyses were completed using Cytobank (cytobank. org) (Kotecha et al, 2010). Paired $t$ tests were used to compare samples.

\section{Flow cytometry-acute adult V-SVZ dissociation}

In the case of acute adult V-SVZ dissociation, published dissociation protocols were adapted for mouse tissue (Leelatian et al., 2017). Periventricular tissues were dissected from $15 \mathrm{C} 57 \mathrm{BL} / 6$ J postnatal day-30 mice and pooled. Tissue pieces were minced with microknives, collected in 15-ml conical tubes (0553859B; Corning) using cold PIPES buffer, and centrifuged at $100 \mathrm{~g}$ for $5 \mathrm{~min}$ at room temperature. Post spinning, the cells were dissociated in a total volume of $5 \mathrm{ml}: 4.9 \mathrm{ml}$ of DMEM-F12 + Glutamax (10565018; Thermo Fisher Scientific), $50 \mu \mathrm{l}$ of $100 \times$ Collagenase II (6885; SigmaAldrich), and $50 \mu$ lof $100 \times$ DNase I (DN25; Sigma-Aldrich) by mixing followed by incubation at $37^{\circ} \mathrm{C}, 5 \% \mathrm{CO}_{2}$ on a nutator for $30 \mathrm{~min}$. These conditions were chosen as they were optimal for cell viability during tissue dissociation (Leelatian et al., 2017). The resulting mixture was then strained through a 70- $\mu$ m cell strainer followed by a $40-\mu \mathrm{m}$ cell strainer using warm DMEM-F12 + GlutaMax media. The strained mixture was then centrifuged at $100 \mathrm{~g}$ for $10 \mathrm{~min}$ at room temperature, and the supernatant was discarded. Pellet was resuspended in $5 \mathrm{ml}$ warm DMEM-F12 + GlutaMax and centrifuged at $100 \mathrm{~g}, 10 \mathrm{~min}$ at room temperature, and the supernatant was discarded. The cells were treated with ACK lysis buffer for 1 min at room temperature followed by the addition of an equivalent volume of warm DMEM-F12 + GlutaMax media. This mixture was then centrifuged at $100 \mathrm{~g}, 10 \mathrm{~min}$ at room temperature, and the supernatant was discarded. Cell pellets were resuspended in warm DMEM-F12 + GlutaMax with Alexa Fluor 700-SE dye for 10 min to label non-intact cells. Subsequently, the cells were fixed with a final concentration of $1.6 \%$ paraformaldehyde for $20 \mathrm{~min}$ at room temperature, washed with $1 \times$ PBS, and spun for 5 min at $800 \mathrm{~g}$ at room temperature. After washing, surface antibody staining was conducted for EGFR-biotin, CD133, and CD24 for 30 min to $1 \mathrm{~h}$ at room temperature in Brilliant buffer; cells were washed with 1× PBS-BSA; and then subjected to secondary staining with streptavidin-BV786 for $30 \mathrm{~min}$ to $1 \mathrm{~h}$ at room temperature in Brilliant buffer. The cells were washed with $1 \times$ PBS-BSA, spun for $5 \mathrm{~min}$ at $800 \mathrm{~g}$ at room temperature, and resuspended in the void volume by vortexing after decanting. $1 \mathrm{ml}$ of ice-cold $70 \%$ ethanol was added to cell pellets and the tubes were stored at $-20^{\circ} \mathrm{C}$ for 20 min to permeabilize cells. The cells were then washed with $1 \times$ PBS-BSA and spun for 5 min at $800 \mathrm{~g}$ at room temperature. Intracellular staining was conducted for DCX, GFAP, and either $p-S 6$ S240/244 or p-4EBP1 T37/46 for 30 min to $1 \mathrm{~h}$ at room temperature. The experiments were run on a BD LSR II 5-laser instrument. Single fluorophore-labeled beads were used as compensation controls and fluorescence-minus-one tubes were created 
for the phosphoprotein channel to assess background signal. Gating for V-SVZ population was completed using cell size controls for comparison (MV411 cells for smaller size and U87 cells for large size). All antibody clones and dilutions are listed in Table S1. All analyses were completed using Cytobank software (cytobank.org).

\section{V-SVZ culture-conditioned media experiments}

Passage 2 V-SVZ NSPCS from P2 mice were plated at an equal number across all samples. Approximately $24 \mathrm{~h}$ after plating, a complete medium change was performed. $24 \mathrm{~h}$ later, the medium was swapped between wells of one set of dorsal and ventral cells from each sample using a 0.22- $\mu \mathrm{m}$ filter to prevent any cross-well cellular contamination. Control cells had media removed, filtered, and replaced in the same well. $24 \mathrm{~h}$ after media exchange, the cells were collected for flow cytometry. A paired $t$ test was performed to determine statistical significance.

\section{Immunostaining-mouse tissue}

50-60- $\mu$ m sections were cut using a Leica SM 2010R sliding microtome with a Physitemp freezing stage (P2-P7 mice at $60 \mu \mathrm{m}$, P30 and older at $50 \mu \mathrm{m}$ ) and stored at $-20^{\circ} \mathrm{C}$ in 24 -well dishes filled with antifreeze solution (Lu \& Haber, 1992). Frozen P7 brains from Tsc2 ablation studies were sectioned at $8-\mu \mathrm{m}$ intervals by the Translational Pathology Shared Resource. Floating sections were incubated in blocking solution (PBS/1\% normal donkey serum $/ 1 \%$ $\mathrm{BSA} / 0.1 \%$ Triton $\mathrm{X}-100$ ) for $30 \mathrm{~min}$ at room temperature and then incubated with primary antibodies overnight at $4^{\circ} \mathrm{C}$ (see Table S1 for antibodies and dilutions). The sections were washed for $5 \mathrm{~min}$ three times with $1 \times$ PBS the following day and then incubated with secondary antibodies and DAPI $(1: 10,000)$ for $2-3 \mathrm{~h}$ at room temperature. The sections were washed for 5 min three times with $1 \times$ PBS and mounted on Coler Frost plus microscope slides (12550-16; Thermo Fisher Scientific). Once dry, the slides were rinsed with $\mathrm{ddH} 20$ followed by the addition of mounting media (Mowiol) and a coverslip. Frozen sections on slides were treated the same; however, they were stored in a humidifier chamber during staining.

\section{Immunostaining-human tissue}

Tissue sections embedded in paraffin were dry-baked vertically for 30 min at $55^{\circ} \mathrm{C}$ in Coplin jars and then cooled to room temperature. De-paraffinizing, rehydrating, and unmasking were completed using Trilogy buffer (920P-09; Cell Marque) and a 16-min antigen retrieval in a pressure cooker. The slides were washed with $1 \times$ PBS and incubated in blocking solution (PBS/1\% normal donkey serum/ 1\% BSA/0.1\% Triton $\mathrm{X}-100$ ) for 30 min at room temperature and then incubated with primary antibodies overnight at $4^{\circ} \mathrm{C}$ in a humidifier chamber (See Table S1 for antibodies and dilutions). No primary controls (NPCS) did not receive primary antibody on the transcription factor channel. The sections were washed for 5 min three times with $1 \times$ PBS the following day and then incubated with secondary antibodies and DAPI $(1: 10,000)$ for $1-2 \mathrm{~h}$ at room temperature. The sections were washed for 5 min three times with $1 \times$
PBS and mounted on SuperFrost Plus Microscope Slides (12-550-16; Thermo Fisher Scientific). Once dry, the slides were rinsed with $\mathrm{ddH} 2 \mathrm{O}$ followed by the addition of mounting media (Mowiol) and a coverslip.

\section{Image quantification-transcription factors in cultures}

Dorsal and ventral V-SVZ subregions were dissected from six postnatal day-2 CD1 mice and cultured for two passages before plating on eight-well chamber slides. Dorsal and ventral cultures were grown to confluence before fixation and staining. The cells were stained with DAPI, PAX6 (BioLegend), and NKX2.1 (Santa Cruz) (see Table S1 for dilutions). Three fields per well were imaged using a Zeiss LSM710 confocal microscope. Transcription factor expression was quantified using FIJI (ImageJ), first by segmenting total nuclei per field, followed by PAX6 and NKX2.1-positive nuclei identification per field. The transcription factor percent positive was averaged across the three fields for each biological replicate. Finally, a paired $t$ test was used to compare transcription factor expression in dorsal versus ventral cultures across six biological replicates.

\section{Image quantification-mouse V-SVZ}

20x confocal tilescan images and $63 \times$ confocal V-SVZ subregion images were obtained using the Zeiss LSM880 microscope. The freehand tool in ImageJ was used to identify positive or negative cells of interest on the lineage-identifying channel (DCX or Mash1), and the "Select $\rightarrow$ Restore Selection" tool was used to overlay the freehand cell outline onto the phosphoprotein channel being analyzed. Mean gray values (MGV) for the phosphoprotein channel of interest were recorded, and background fluorescence on the phosphoprotein channel was subtracted from each MGV value. MGV values for both dorsal and ventral were analyzed using GraphPad Prism software; Wilcoxon signed rank tests were used to compare dorsal and ventral values. Violin plots were generated using R-project software.

\section{Image quantification-human SEGAs and tubers}

Whole slide imaging was performed at the Digital Histology Shared Resource at the Vanderbilt University Medical Center (www.mc. vanderbilt.edu/dhsr). For each SEGA and tuber sample, H+E, NPC, EMX1-stained, and NKX2.1-stained images were aligned to allow quantification of the same region across $5-\mu \mathrm{m}$ serial sections. Within regions identified as idiopathic without high blood cell infiltration by a pathologist (BC Mobley), CellProfiler was used to segment DAPI+ nuclei across 4-5 1,300 × 1,300- $\mu \mathrm{m}$ fields per sample and to measure integrated intensity of NPC, EMX1, and NKX2.1 as well as the nuclear area for each identified nucleus. All data were imported into Cytobank (Cytobank.org) and EMX1+ and NKX2.1+ nuclei were gated by using the NPC nuclei as a negative control. The \% positive signal for EMX1 and NKX2.1 was determined by gating on biaxial plots of integrated intensity versus area to account for any differences in the size of nuclei. Wilcoxon signed rank tests were used to analyze the results. 


\section{Image quantification-OPP}

For OP-puromycin labeling, the Thermo Fisher Scientific Click-iT Plus Protein Synthesis Assay with the Ax647 fluorophore was used according to the manufacturer's instructions. All images were acquired with identical settings on a Zeiss LSM880 confocal microscope. For analysis, cell nuclei were segmented in CellProfiler using DAPI staining, and median OPP pixel intensity was calculated for each segmented nucleus. Median nuclear OPP intensity per field was evaluated because of high confluence in cultures preventing accurate assignment of cytoplasmic regions to nuclei. In addition, OPP staining overlapped with nuclei in the vast majority of cases. The box and whisker plot was drawn in $\mathrm{R}$ as previously described (https://ggplot2.tidyverse.org/reference/geom_boxplot.html).

\section{Real-time quantitative reverse transcription PCR (qRT-PCR)}

Total RNA from passage 3 dorsal and ventral cultures from 5 wild-type littermates were isolated using standard protocols (Ihrie et al, 2011). Transcript expression was measured in triplicate with Taqman assays (Applied Biosystems) for Ubc (Mm01201237_m1), Nkx2.1 (Mm00447558_m1), Nkx6.2 (Mm00807812_g1), and Pax6 (Mm00443081_m1), using a CFX96 Real-Time System on a C1000 Thermal Cycler (Bio-Rad). Relative expression of transcripts was calculated in Excel using the delta-delta CT method with Ubc as an endogenous control. A paired $t$ test in GraphPad Prism was used to determine statistical significance.

\section{Measurement of V-SVZ culture doubling times}

After V-SVZ NSPCs were dissected and cultured from the dorsal and ventral regions of C57BL/ 6 (C57) wild-type mice, they were passaged every $4 \mathrm{~d}$ with equal numbers of live cells replated each time. At each passage, live cells were carefully counted using a hemacytometer and trypan blue staining. Five fields of view were counted per sample at each time point. A paired t test in GraphPad Prism was used to determine statistical significance in the doublings per day between the ventral and dorsal cells.

\section{Quantification and statistical analysis}

All tests are specified in figures and figure legends. GraphPad Prism was used for all analyses unless otherwise specified. For sample size estimation in region-specific removal of $T s c 2$, the Power and Sample Size (PS) software (Vanderbilt Biostatistics resource) was used with the assumption of differences in tumor size or latency of $30 \%$ or more, an effect size smaller than size differences in published TSC models (Zhou et al, 2011; Feliciano et al, 2012).

\section{Supplementary Information}

Supplementary Information is available at https://doi.org/10.26508/lsa. 201800218.

\section{Acknowledgements}

The authors thank the Ihrie and Irish labs and Christopher VE Wright for helpful discussions on data and figure organization, Brittany Parker (Fu lab),
Amanda Jurewicz, and Ethan Chervonski (Ihrie lab) for assistance with the collection of mouse samples, and David K Flaherty (VUMC Flow Cytometry Shared Resource) for helpful discussions. Confocal microscopy experiments were performed in part through the use of the Vanderbilt University Cell Imaging Shared Resource (supported by NIH grants S10 1S100D021630-01, CA68485, DK20593, DK58404, DK59637, and EY08126). Whole slide imaging of TSC SEGA and tuber tissue was performed at the Digital Histology Shared Resource at Vanderbilt University Medical Center (www.mc.vanderbilt.edu/dhsr). Flow Cytometry experiments were performed in the Vanderbilt University Medical Center Flow Cytometry Shared Resource (supported by the Vanderbilt Ingram Cancer Center (P30 CA68485) and the Vanderbilt Digestive Disease Research Center (DK058404)). The Vanderbilt Translational Pathology Shared Resource is supported by $\mathrm{NCl} / \mathrm{NIH}$ Cancer Center Support Grant 2P30 CA068485-14 and the Vanderbilt Mouse Metabolic Phenotyping Center Grant 5U24DK059637-13. This work was supported by NIH 2T32CA009592 (GV Rushing), F31 NS096908 (GV Rushing), NIH/ NINDS NS096238 (RA I hrie), NCI R00 CA143231 (JM Irish), NINDS 1R01 NS078289 (KC ESS), DOD W81XWH-16-1-0171/TS150037 (RA Ihrie), a research grant from the Tuberous Sclerosis Alliance (RA Ihrie), the VICC ACS-IRG 15-169-56 Pilot Project Grant (RA Ihrie), a grant from the VICC Michael David Greene Brain Cancer Research Fund, and a VICC Young Ambassadors Discovery Grant (RA Ihrie).

\section{Author Contributions}

GV Rushing: conceptualization, funding acquisition, validation, investigation, visualization, methodology, and writing-original draft, review, and editing.

AA Brockman: investigation.

MK Bollig: investigation.

N Leelatian: visualization and methodology.

BC Mobley: resources.

JM Irish: supervision, visualization, and methodology.

KC Ess: resources, supervision, funding acquisition, and writing-review and editing.

C Fu: resources and funding acquisition.

RA Ihrie: conceptualization, supervision, funding acquisition, visualization, methodology, and writing-original draft, review, and editing.

\section{Conflict of Interest Statement}

JM Irish is a co-founder and board member at Cytobank Inc. and received research support from Incyte Corp., Janssen, and Pharmacyclics. The other authors declare no conflict of interest.

\section{References}

Baser A, Skabkin M, Kleber S, Dang Y, Gulculer Balta GS, Kalamakis G, Gopferich M, Ibanez DC, Schefzik R, Lopez AS, et al (2019) Onset of differentiation is post-transcriptionally controlled in adult neural stem cells. Nature 566: 100-104. doi:10.1038/s41586-019-0888-x

Codega P, Silva-Vargas V, Paul A, Maldonado-Soto AR, Deleo AM, Pastrana E, Doetsch F (2014) Prospective identification and purification of quiescent adult neural stem cells from their in vivo niche. Neuron 82: 545-559. doi:10.1016/j.neuron.2014.02.039

Crino PB, Nathanson KL, Henske EP (2006) The tuberous sclerosis complex. N Engl J Med 355: 1345-1356. doi:10.1056/nejmra055323

Delgado RN, Lim DA (2015) Embryonic Nkx2.1-expressing neural precursor cells contribute to the regional heterogeneity of adult V-SVZ neural stem cells. Dev Biol 407: 265-274. doi:10.1016/j.ydbio.2015.09.008 
Delgado RN, Lu C, Lim DA (2016) Maintenance of neural stem cell regional identity in culture. Neurogenesis (Austin) 3: e1187321. doi:10.1080/ 23262133.2016.1187321

Ess KC, Kamp CA, Tu BP, Gutmann DH (2005) Developmental origin of subependymal giant cell astrocytoma in tuberous sclerosis complex. Neurology 64: 1446-1449. doi:10.1212/01.wnl.0000158653.81008.49

Feliciano DM, Quon JL, Su T, Taylor MM, Bordey A (2012) Postnatal neurogenesis generates heterotopias, olfactory micronodules and cortical infiltration following single-cell Tsc1 deletion. Hum Mol Genet 21: 799-810. doi:10.1093/hmg/ddr511

Foerster P, Daclin M, Asm S, Faucourt M, Boletta A, Genovesio A, Spassky N (2017) mTORC1 signaling and primary cilia are required for brain ventricle morphogenesis. Development 144: 201-210. doi:10.1242/ dev. 138271

Fu C, Ess KC (2013) Conditional and domain-specific inactivation of the Tsc2 gene in neural progenitor cells. Genesis 51: 284-292. doi:10.1002/ dvg.22377

Gorski JA, Talley T, Qiu M, Puelles L, Rubenstein JL, Jones KR (2002) Cortical excitatory neurons and glia, but not GABAergic neurons, are produced in the Emx1-expressing lineage. J Neurosci 22: 6309-6314. doi:10.1523/ jneurosci.22-15-06309.2002

Guerrero-Cazares H, Gonzalez-Perez O, Soriano-Navarro M, Zamora-Berridi G, Garcia-Verdugo JM, Quinones-Hinojosa A (2011) Cytoarchitecture of the lateral ganglionic eminence and rostral extension of the lateral ventricle in the human fetal brain. J Comp Neurol 519: 1165-1180. doi:10.1002/cne.22566

Hack MA, Saghatelyan A, de Chevigny A, Pfeifer A, Ashery-Padan R, Lledo PM, Gotz M (2005) Neuronal fate determinants of adult olfactory bulb neurogenesis. Nat Neurosci 8: 865-872. doi:10.1038/nn1479

Hang JF, Hsu CY, Lin SC, Wu CC, Lee HJ, Ho DM (2017) Thyroid transcription factor-1 distinguishes subependymal giant cell astrocytoma from its mimics and supports its cell origin from the progenitor cells in the medial ganglionic eminence. Mod Pathol 30: 318-328. doi:10.1038/ modpathol.2016.205

Hartman NW, Lin TV, Zhang L, Paquelet GE, Feliciano DM, Bordey A (2013) mTORC1 targets the translational repressor 4E-BP2, but not S6 kinase $1 / 2$, to regulate neural stem cell self-renewal in vivo. Cell Rep 5: 433-444. doi:10.1016/j.celrep.2013.09.017

Hewer E, Vajtai I (2015) Consistent nuclear expression of thyroid transcription factor 1 in subependymal giant cell astrocytomas suggests lineagerestricted histogenesis. Clin Neuropathol 34: 128-131. doi:10.5414/ np300818

Hsu PP, Kang SA, Rameseder J, Zhang Y, Ottina KA, Lim D, Peterson TR, Choi Y, Gray NS, Yaffe MB, et al (2011) The mTOR-regulated phosphoproteome reveals a mechanism of mTORC1-mediated inhibition of growth factor signaling. Science 332: 1317-1322. doi:10.1126/science.1199498

Ihrie RA, Shah JK, Harwell CC, Levine JH, Guinto CD, Lezameta M, Kriegstein AR, Alvarez-Buylla A (2011) Persistent sonic hedgehog signaling in adult brain determines neural stem cell positional identity. Neuron 71: 250-262. doi:10.1016/j.neuron.2011.05.018

Irish JM, Myklebust JH, Alizadeh AA, Houot R, Sharman JP, Czerwinski DK, Nolan GP, Levy R (2010) B-cell signaling networks reveal a negative prognostic human lymphoma cell subset that emerges during tumor progression. Proc Natl Acad Sci U S A 107: 12747-12754. doi:10.1073/ pnas.1002057107

Katz JS, Milla SS, Wiggins GC, Devinsky O, Weiner HL, Roth I (2012) Intraventricular lesions in tuberous sclerosis complex: A possible association with the caudate nucleus. I Neurosurg Pediatr 9: 406-413. doi:10.3171/2011.12.peds11418

Kessaris N, Fogarty M, lannarelli P, Grist M, Wegner M, Richardson WD (2006) Competing waves of oligodendrocytes in the forebrain and postnatal elimination of an embryonic lineage. Nat Neurosci 9: 173-179. doi:10.1038/nn1620
Kohwi M, Osumi N, Rubenstein JL, Alvarez-Buylla A (2005) Pax6 is required for making specific subpopulations of granule and periglomerular neurons in the olfactory bulb. J Neurosci 25: 6997-7003. doi:10.1523/ jneurosci.1435-05.2005

Kotecha N, Krutzik PO, Irish JM (2010) Web-based analysis and publication of flow cytometry experiments. Curr Protoc Cytom doi:10.1002/ 0471142956.cy1017s53

Krueger DA, Northrup H, International Tuberous Sclerosis Complex Consensus G (2013) Tuberous sclerosis complex surveillance and management: Recommendations of the 2012 International tuberous sclerosis complex Consensus Conference. Pediatr Neurol 49: 255-265. doi:10.1016/j.pediatrneurol.2013.08.002

Leelatian N, Doxie DB, Greenplate AR, Sinnaeve J, Ihrie RA, Irish JM (2017) Preparing viable single cells from human tissue and tumors for cytomic analysis. Curr Protoc Mol Biol 118: 25C 21 21-25C 2123. doi:10.1002/cpmb.37

Llorens-Bobadilla E, Zhao S, Baser A, Saiz-Castro G, Zwadlo K, Martin-Villalba A (2015) Single-cell transcriptomics reveals a population of dormant neural stem cells that become activated upon brain injury. Cell Stem Cell 17: 329-340. doi:10.1016/j.stem.2015.07.002

Lois C, Alvarez-Buylla A (1994) Long-distance neuronal migration in the adult mammalian brain. Science 264: 1145-1148. doi:10.1126/ science. 8178174

Lopez-Juarez A, Howard J, Ullom K, Howard L, Grande A, Pardo A, Waclaw R, Sun YY, Yang D, Kuan CY, et al (2013) Gsx2 controls region-specific activation of neural stem cells and injury-induced neurogenesis in the adult subventricular zone. Genes Dev 27: 1272-1287. doi:10.1101/ gad. 217539.113

Louis DNOH, Wiestler OD, Cavenee WK (2016) World Health Organization Histological Classification of Tumours of the Central Nervous System. Lyon, France: International Agency for Research on Cancer.

Lu W, Haber SN (1992) In situ hybridization histochemistry: A new method for processing material stored for several years. Brain Res 578: 155-160. doi:10.1016/0006-8993(92)90243-3

Magri L, Cominelli M, Cambiaghi M, Cursi M, Leocani L, Minicucci F, Poliani PL, Galli R (2013) Timing of mTOR activation affects tuberous sclerosis complex neuropathology in mouse models. Dis Model Mech 6: 1185-1197. doi:10.1242/dmm.012096

Martin KR, Zhou W, Bowman MJ, Shih J, Au KS, Dittenhafer-Reed KE, Sisson KA, Koeman J, Weisenberger DJ, Cottingham SL, et al (2017) The genomic landscape of tuberous sclerosis complex. Nat Commun 8: 15816. doi:10.1038/ncomms15816

Merkle FT, Fuentealba LC, Sanders TA, Magno L, Kessaris N, Alvarez-Buylla A (2014) Adult neural stem cells in distinct microdomains generate previously unknown interneuron types. Nat Neurosci 17: 207-214. doi:10.1038/nn.3610

Merkle FT, Mirzadeh Z, Alvarez-Buylla A (2007) Mosaic organization of neural stem cells in the adult brain. Science 317: 381-384. doi:10.1126/ science. 1144914

Northrup H, Krueger DA, International Tuberous Sclerosis Complex Consensus G (2013) Tuberous sclerosis complex diagnostic criteria update: Recommendations of the 2012 linternational tuberous sclerosis complex Consensus Conference. Pediatr Neurol 49: 243-254. doi:10.1016/j.pediatrneurol.2013.08.001

Paliouras GN, Hamilton LK, Aumont A, Joppe SE, Barnabe-Heider F, Fernandes $\mathrm{KJ}$ (2012) Mammalian target of rapamycin signaling is a key regulator of the transit-amplifying progenitor pool in the adult and aging forebrain. J Neurosci 32: 15012-15026. doi:10.1523/jneurosci.224812.2012

Pastrana E, Cheng LC, Doetsch F (2009) Simultaneous prospective purification of adult subventricular zone neural stem cells and their progeny. Proc Natl Acad Sci U S A 106: 6387-6392. doi:10.1073/ pnas.0810407106 
Sanai N, Nguyen T, Ihrie RA, Mirzadeh Z, Tsai HH, Wong M, Gupta N, Berger MS, Huang E, Garcia-Verdugo JM, et al (2011) Corridors of migrating neurons in the human brain and their decline during infancy. Nature 478: 382-386. doi:10.1038/nature10487

Sawamoto K, Wichterle H, Gonzalez-Perez O, Cholfin JA, Yamada M, Spassky N, Murcia NS, Garcia-Verdugo JM, Marin O, Rubenstein JL, et al (2006) New neurons follow the flow of cerebrospinal fluid in the adult brain. Science 311: 629-632. doi:10.1126/science.1119133

Saxton RA, Sabatini DM (2017) mTOR signaling in growth, metabolism, and disease. Cell 169: 361-371. doi:10.1016/j.cell.2017.03.035

Spidlen J, Breuer K, Rosenberg C, Kotecha N, Brinkman RR (2012) FlowRepository: A resource of annotated flow cytometry datasets associated with peer-reviewed publications. Cytometry A 81: 727-731. doi:10.1002/cyto. a.22106

Sussel L, Marin O, Kimura S, Rubenstein JL (1999) Loss of Nkx2.1 homeobox gene function results in a ventral to dorsal molecular respecification within the basal telencephalon: Evidence for a transformation of the pallidum into the striatum. Development 126: 3359-3370.

Waclaw RR, Allen Z) 2nd, Bell SM, Erdelyi F, Szabo G, Potter SS, Campbell K (2006) The zinc finger transcription factor Sp8 regulates the generation and diversity of olfactory bulb interneurons. Neuron 49: 503-516. doi:10.1016/j.neuron.2006.01.018
Xu Q, Tam M, Anderson SA (2008) Fate mapping Nkx2.1-lineage cells in the mouse telencephalon. J Comp Neurol 506: 16-29. doi:10.1002/ cne. 21529

Young KM, Fogarty M, Kessaris N, Richardson WD (2007) Subventricular zone stem cells are heterogeneous with respect to their embryonic origins and neurogenic fates in the adult olfactory bulb. J Neurosci 27: 8286-8296. doi:10.1523/ jneurosci.0476-07.2007

Zhou J, Shrikhande G, Xu J, McKay RM, Burns DK, Johnson JE, Parada LF (2011) Tsc1 mutant neural stem/progenitor cells exhibit migration deficits and give rise to subependymal lesions in the lateral ventricle. Genes Dev 25: 1595-1600. doi:10.1101/gad.16750211

Zordan P, Cominelli M, Cascino F, Tratta E, Poliani PL, Galli R (2018) Tuberous sclerosis complex-associated CNS abnormalities depend on hyperactivation of mTORC1 and Akt. J Clin Invest 128: 1688-1706. doi:10.1172/jci96342

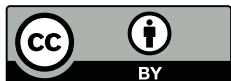

License: This article is available under a Creative Commons License (Attribution 4.0 International, as described at https://creativecommons.org/ licenses/by/4.0/). 